\title{
Erratum to: Integrated Groundwater Management
}

\author{
Anthony J. Jakeman, Olivier Barreteau, Randall J. Hunt, \\ Jean-Daniel Rinaudo, and Andrew Ross
}

(C) The Author(s) 2016

A.J. Jakeman et al. (eds.), Integrated Groundwater Management, DOI 10.1007/978-3-319-23576-9

In the book titled "Integrated Groundwater Management" the affiliation of the author Prof. "Olivier Barreteau" in the copyright page of FM is incorrect and should read as follows:

Olivier Barreteau

IRSTEA, UMR G-EAU

Montpellier, France

The updated original online version for this book can be found at

DOI 10.1007/978-3-319-23576-9 